Behnke, Thomas; Laux, Eva-Maria; Hoffmann, Katrin; Peters, Sven; Haueisen, Jens;

Klemm, Matthias; Resch-Genger, Ute:

\title{
Simple approaches to fluorescence lifetime standards using dye-quencher pairs
}

Zuerst erschienen in: Biomedical Engineering = Biomedizinische Technik. - Berlin [u.a.] : de Gruyter. - 57 (2012), Suppl. 1, Track-E, p. 613.

Erstveröffentlichung: $\quad$ 2012-08-30

ISSN (online): $\quad$ 1862-278X

ISSN (print): $\quad$ 0013-5585

DOI: $\quad 10.1515 / \mathrm{bmt}-2012-4499$

[Zuletzt gesehen: 2019-08-12]

„Im Rahmen der hochschulweiten Open-Access-Strategie für die Zweitveröffentlichung identifiziert durch die Universitätsbibliothek IImenau."

"Within the academic Open Access Strategy identified for deposition by Ilmenau University Library."

„Dieser Beitrag ist mit Zustimmung des Rechteinhabers aufgrund einer (DFGgeförderten) Allianz- bzw. Nationallizenz frei zugänglich."

"This publication is with permission of the rights owner freely accessible due to an Alliance licence and a national licence (funded by the DFG, German

Research Foundation) respectively." 


\title{
Simple Approaches to Fluorescence Lifetime Standards Using Dye-Quencher Pairs
}

\author{
T. Behnke ${ }^{1}$, E. M. Laux ${ }^{1}$, K. Hoffmann ${ }^{1}$, S. Peters ${ }^{2}$, J. Haueisen ${ }^{3}$, M. Klemm ${ }^{3}$, and \\ Ute Resch-Genger ${ }^{1}$
}

\author{
${ }^{1}$ BAM Federal Institute for Materials Research and Testing, Division 1.10, D-12489 \\ Berlin, Germany.E-mail: ute.resch@bam.de \\ ${ }^{2}$ University Hospital Jena, Department of Ophthalmology, Jena, Germany \\ ${ }^{3}$ Ilmenau University of Technology, Institute for Biomedical Engineering and \\ Informatics, Ilmenau, Germany
}

\section{Introduction}

Photoluminescence techniques are amongst the most widely used tools in the material and life sciences, with new and exciting applications continuously emerging. Advantages include their comparative ease of use, unique sensitivity, non-invasive character, and potential for multiplexing, remote sensing, and miniaturization [1-4]. Increasing applications of fluorescence techniques in the life sciences and emerging medical applications of fluorescence microscopic techniques including $1 \mathrm{P}$ and $2 \mathrm{P}$ fluorescence microscopy combined with fluorescence lifetime imaging (FLIM) in e.g. in vivo eye diagnostics boosted the demand for robust, easy-to-use, and reliable fluorescence standards to ensure the reliability and comparability of fluorescence data. This includes fluorescence standards for the consideration of instrument-specific spectral and intensity distortions of measured signals and instrument performance validation, fluorescence intensity standards for the quantification of measured intensities and for signal referencing, and lately, also fluorescence lifetime standards [1,4-8].

\section{Methods}

Time resolved fluorometry and 2P FLIM were used to study the fluorescence decay behavior of several xanthene dyes in the presence of different concentrations of the quenchers $\mathrm{KI}, \mathrm{Cu}(\mathrm{II}) \mathrm{ClO}_{4}$, triethylamine, and tryptophan in aqueous solution.

\section{Results}

The fluorescence decays obtained for five xanthene dyes in aqueous solution in the presence of different concentrations of four quenchers were compared focusing on the size of the resulting lifetimes / realizable degree of quenching and the decay kinetics. With a fluorescence lifetime of 4 ns and monoexponential decay kinetics without quencher and quencher-tunable lifetimes between $4 \mathrm{~ns}$ and $0.2 \mathrm{~ns}$, the pair rhodamine 6G-KI in PBS revealed the most intriguing properties.

\section{Conclusion}

We identified a first fluorophore-quencher pair as lifetime standard candidate. Ongoing studies focus on the ease of use of this approach under routine measurement conditions and the thermal and photochemical stability of this system and its reproducibility.

References: [1] P.C. DeRose et al. in: Standardization and Quality Assurance in Fluorescence Measurements I: Techniques, U. Resch-Genger (ed.), Springer Series on Fluorescence, O. S. Wolfbeis (ed.), vol. 5, 2008, pp. 33. [2] K. Hoffmann, R. Nitschke, U. Resch-Genger in: Standardization and Quality Assurance in Fluorescence Measurements II: Bioanalytical and Biomedical Applications, U. Resch-Genger (ed.), Springer Series on Fluorescence, O. S. Wolfbeis, vol. 6, 2008, pp. 89. [3] U. Resch-Genger et al., J. Fluoresc. 2005, 15, 337. [5] L. Wang et al., Biophotonics Int. 2005, 42. [6] P. C. DeRose, U. Resch-Genger, Anal. Chem. 2010. [7] N. Boens et al., Anal. Chem. 2007. [8] M. vandeVen et al., J. Fluoresc. 2005. 